UDC: $37.02: 801.563 .1 \quad$ https://doi.org/10.22190/JTESAP2103307O

Original scientific paper

\title{
ROLE OF ONLINE DISCUSSION FORUMS IN ENHANCING USERS' COGNITIVE SKILLS
}

\author{
Charles Ononiwu
}

Alex Ekwueme Federal University Ndufu-Alike, Nigeria

\begin{abstract}
The study examines the role of online discussion forums (ODFs) in the learning process, using Garrison, Anderson and Archer's (2000) Community of Inquiry (CoI) model, particularly on the development of metacognitive skills, higher-order thinking skills and collaborative learning, all of which provide the impetus for workplace skills, such as analytical skills and teamwork. To achieve that, the study adopts the qualitative content analysis method to examine learners' text submissions in the ODF. An ODF was set up on www.easyclass.com (an online learning management system), and students were invited to post their submissions in the forum bi-weekly for three months. A series of prompts from the course instructor were given to the learners in the ODF bi-weekly after the f2f classroom interaction. The prompts were designed to elicit students' responses, which would provide evidence of students' learning, such as application of theory to practice, the abstraction of major ideas from a text, appropriate inferences and synthesis of ideas, etc. The analysis of the findings demonstrated evidence of metacognitive awareness, which was facilitated by the asynchronous nature of the discussion forum, as it gives learners sufficient time to engage in thorough research and careful thought before posting their submission. The findings also demonstrated that peer-to-peer knowledge dissemination is best stimulated using the $O D F$, as it gives learners opportunities to participate actively and to collaborate with their peers in the learning process.
\end{abstract}

Key words: online discussion forum, computer-mediated communication metacognitive skills, collaboration, higher education

\section{INTRODUCTION}

Technology-enabled learning is fast becoming pervasive in higher education worldwide and is being adopted by more and more high schools and higher educational institutions. Available evidence shows that the use of Information and Communication Technology (ICT) in the educational process is spreading faster than any other form of curricula change and innovation in the world, and advances in technology have led to a significant shift in the instructional processes (Hu et al. 2018). Hawkins and Rudy (2008) report that by 2007 , over $90 \%$ of US universities and colleges had established one or more LMStype products for student and faculty use.

Submitted October $10^{\text {th }}, 2020$, accepted for publication January $16^{\text {th }}, 2021$

Corresponding author: Charles Ononiwu. Alex Ekwueme Federal University Ndufu-Alike, 53, Nsugbe Street, Nigeria

E-mail: charles.ononiwu@gmail.com

두 2021 by University of Niš, Serbia | Creative Commons License: CC BY-NC-ND 
Many factors are responsible for the adoption of technology-mediated learning, one of the most prominent ones certainly being globalization. Such factors inform the pressure on higher educational institutions (HEIs) to integrate new technologies, particularly online learning. Technology is thought to redress HEI challenges especially faced in developing countries, such as overcrowded classrooms, lack of meaningful note taking skills during face-to-face classroom contact, and the culture of developing students' capacity to pass examination through memorisation as well as dwindling or obsolete equipment and limited human resources (Dooga, 2010). Technology-mediated learning cannot be more desirable than in this era of pandemic, as it integrates both safety and survival with a continuous learning experience.

Most institutions of higher learning in sub-Saharan Africa started making efforts to integrate technology in teaching, learning, research and administration within the first decade of the $21^{\text {st }}$ century, with the massive installation of ICT infrastructure: servers, VSAT for internet connection, and the establishment of computer laboratories for students. However, blended learning is yet to take off in earnest compared to the conventional face-to-face (f2f) class interaction. Besides, large classes have made it increasingly challenging for students to participate in class discussions to synthesise and share ideas actively. The shy ones hide under the pretence of large classes so as not to fully participate in f2f class interaction. Students are easily distracted by their poor note-taking skills, as they attempt to write everything the lecturer says in class, thereby not benefiting fully from lectures. Such student expectations also limit what lecturers could achieve in a lesson. If they proceeded at the writing pace of the students, only a few topics would be treated, and if the lecturers moved at their pace, most students would be left behind and the learning objectives for the course would not be achieved.

The higher educational institutions are increasingly under pressure from government and industries to produce graduates that would be relevant to present industrial and public needs. Worried by the declining quality of instruction in higher institutions within subSaharan Africa, Professor Ibrahim Bello-Kano (in a roundtable program on reviving the culture of debate and critical thinking in the Nigerian university system organized by the Centre for Information Technology and Development CITAD, 2019) argued that Nigerian universities have degenerated into "Super Secondary Schools", as the current system does not encourage students to grow critical minds but is targeted at developing their capacity to pass examinations through memorization.

To address these teaching and learning challenges, it was reasoned that if contents were provided to students online before f $2 \mathrm{f}$ class contact, it would help students note down key points and then concentrate on listening actively during face to face lectures and participating fully during the online discussion phase. It is believed that it would help learners to achieve critical thinking and effective application of knowledge, which can result in long-term academic success (Frazer, et al., 2017).

A primary objective of providing content to students online before the f2f class contact and creating an online discussion forum is to promote discourse through inclusive peer participation, leading to layers of text creation and collaboration. In the face to face (f2f) method of teaching, learner participation was achieved through students' collaboration in preparing term papers in groups and presentation of such papers, which formed the basis for class debates and discussions. Students still work in groups and collaborate on class projects. Nevertheless, escalating student enrolments, which have led to overcrowding, have made it increasingly difficult to create opportunities for students to 
participate, debate meaningfully, and share findings of their research efforts with peers in the class setting and thus cross-fertilize ideas.

\subsection{Online discussion forums}

Nandi, Chang and Balbo (2009) describe an online discussion forum as "a ubiquitous communication tool within an online learning environment" and argue that it significantly shapes the types of communication that takes place. They state that online discussion forums have been successfully used as communication tools to scaffold interaction, exchange ideas and share knowledge among learners and instructors. The duo says that the asynchronous nature of online discussion forums enables all participants in the learning process to communicate with each other at any time and in any place without having to find the time for face-to-face (f2f) interaction. Posting in an online forum makes the discussion public and accessible to all at their own time and convenience (Nandi, Hamilton, Harland, \& Warburton, 2011).

Marra, Moore, and Klimczak (2004: 23) identify the discussion forum as a significant component of online courses and claim that "instructors and students rely on these asynchronous forums to engage one another in ways that potentially promote critical thinking, meaningful problem solving, and knowledge construction". Discussing and reflecting on topics online, asynchronously, can be just as beneficial (if not more) as traditional, synchronous, in-class discussion. In the online environment, students can thoughtfully add to a discussion, cogitate on other student contributions and autonomously make meaningful contributions to the subject matter - something that may not be possible in the traditional classroom (Tan, 2016).

\subsection{Research question}

This research examines the value of the online discussion forums as a learning tool. The terms 'social', 'cognitive' and 'teaching' are widespread in the literature on developmental psychology and education that ensure 'collaborative-constructivist' learning experience. In this research, the study adopts Garrison, Anderson and Archer's (2000) social, cognitive and teaching elements to foreground the research questions and analysis. The specific questions the researcher wishes to address then are:

1. If using online discussion forums can mediate the acquisition of higher cognitive functions, in what particular ways does this happen?

2. How do instructors and learners collaborate in ODFs?

3. How do students' contributions to the ODFs demonstrate a deep reflection of what has been learned?

\section{LITERATURE REVIEW}

The study sets the educational context by referring to literature (Lucy \& Wertsch, 1987; Hardman 2011; Kozulin, 2003; Vygotsky 1978) that provides the broad base of the theory of learning. Such literature establishes what constitutes learning from the socio-cultural perspective. According to Vygotsky (1978) "social interaction is the most important stimulus for all learning" (cited in Littlewood 2006). Vygotsky maintains that social interaction provides substantive means by which learning occurs and holds that social interaction plays a 
fundamental role in the development of cognition, arguing that students learn from each other's knowledge, skills and experiences through discussion and interaction.

There is a large body of research that suggests that students' participation in online discussion forum has a positive correlation with their academic performance (Cheng, et al., 2011; Green et al., 2014; Romero, et al., 2013). This could be interaction with symbolic tools or the mediation provided by the expert instructor, or that of the learner's peers. Hardman (2011) defines mediation as "the utilization of cultural artefacts (tools, signs, symbolic and communicative activity) as a means of attaining higher mental functions". Vygotsky's sociocultural theory privileges interaction between social persons as the primary basis for cognitive development. Following the above line of argument, it can be said that the more guided interaction is possible in a learning environment, the more likely will such learners participate, and the more they are able to participate, the more will they be able to share research findings, resources, ideas in a collaborating way, and the more these processes take place, the more will such learners experience cognitive development. Vygotsky associates two different conceptual processes to content learning (Kozulin 2003:32). The first is empirical concepts, which are generally spontaneous. The second is the development of systematic, focused, deliberate, goal-oriented scientific concepts. According to Vygotsky, the former does not add much to a learner's cognitive development because the concepts are based on the existing cognitive mechanisms. It only enhances learner's practical experience. It is the later, the development of scientific concepts that develops the learner's higher cognitive functioning (Kozulin 2003:32).

\subsection{Methodologies used in similar studies}

Allan (2004) reviewed the various methodologies used in studying online discussion forums. According to her, prevalent research approaches range from quantitative measurements of log-in frequencies to descriptive quantitative content analysis that measures frequency of contributions per learner, as well as making inferences from quantitative content analysis for assessing learning processes in online contexts (Kanuka and Anderson, 1998), or applying qualitative content analysis techniques for studying the quality of messages as artefacts of critical thinking and argumentation content (Jeong, 2003). In addition to assessing the quality of forum submissions or assessing the quality of forum messages, other studies have focused on issues around assessing forum submissions in terms of grading or awarding marks.

As more institutions adopt some form of technology-supported learning, online discussion forums have become increasingly utilised in the delivery of university-level courses (Harris and Sandor, 2007). As a result of such wide adoption, many scholars have sought to assess the efficacy of the tool for learning; others have researched the design, implementation, use, and evaluation of online discussion forums (Harris and Sandor, 2007).

Richards (2009) adopted the action research approach to investigate the impact of assessment on discussion forum participation and assessed group work in comparison with the individual involvement and evaluation. While acknowledging the pedagogical value of using online discussion forums, he observed that if online discussion forums are to be an effective tool for learning, something more must be done than just providing the technology.

Gunawardena and Zittle (1997) identify a framework of fundamental concepts or critical elements to identify, group and analyse the quality of online discussion forums. 
They organize these vital elements according to five themes: social presence, interaction, cognitive strategies, collaborative learning, and learner-centered instruction. In doing so, they acknowledge that every online post need not contain all the components. Nevertheless, organizing online posts into such themes frames the analysis in a more systematic, focused and verifiable way. Richards (2009) points out that the role of assessment is to ensure participation, interaction, and where appropriate, collaboration and teamwork, especially in group work, stressing that the focal point of such assessment should be to evaluate cognitive engagement and achievement of course objectives. Some dimensions to consider in such assessment include content, research, writing, relevance, originality, timeliness and interaction. Like Gunawardena and Zittle (1997) cited earlier, these components are a guide to what is to be looked for when assessing learners' online posts.

\subsection{Conceptual framework}

Garrison, Anderson and Archer's (2000) Community of Inquiry (CoI) model is conceivably one of the most recent and tested models on pedagogically computermediated communication, as it projects a tripartite process of generating a meaningful online learning experience, namely, social, cognitive and teaching presence. A community of inquiry is seen as "a group of individuals who collaboratively engage in purposeful critical discourse and reflection to construct personal meaning and confirm mutual understanding" (Garrison, 2011, p.2). The above definition, therefore, engraves interaction and collaboration as the hallmarks of CoI model. The theory identifies and describes the components to look for when examining learning functions in the educational context. The essential features of the CoI model are summarized below.

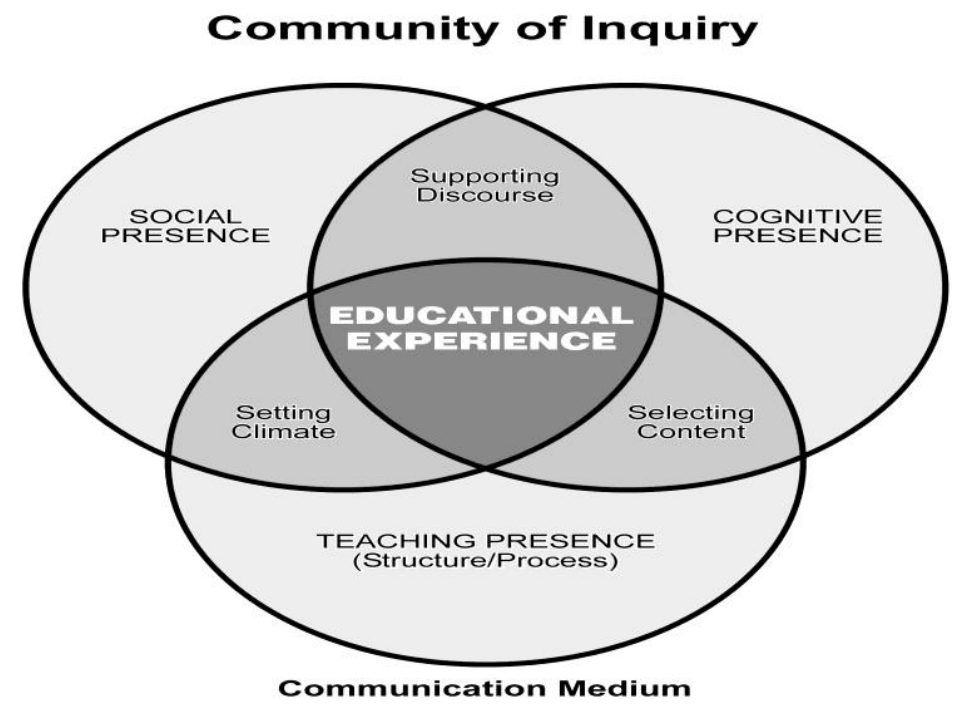

Baron and Maier $(2004,2005)$ took a Community of Inquiry conceptual framework to evaluate cognitive, social and teaching presence at the higher education level. They focus on collaboration, cooperation and decision-making, analysing the asynchronous discussion 
board activity and student debriefs of 86 Civil and Environmental Engineering students who undertook the e-Sim during 2004. Although this research is about roleplaying, one of the enabling tools was the online discussion board (a variant term for an online discussion forum). The authors report that communication within each group in the Community of Inquiry occurred via the group discussion board and email to research and prepare their inquiry submissions to the general discussion board. They conclude that an online learning environment has advantages for a community of inquiry process in that "the asynchronous communication medium of groups, discussion boards and email is both reflective and explicit, and learners have access to unlimited data sources. This allows students to take responsibility and control of their learning through negotiating meaning, diagnosing misconceptions, and challenging accepted beliefs, which are essential ingredients for deep and meaningful learning outcomes" (Garrison and Anderson 2003).

\section{METHODOLOGY}

An Online Discussion Forum was set up on www.easyclass.com (a free learning management system), and students were invited to post their submissions in the Forum. The study adopted Hara, Bonk, \& Angeli (1998) framework for analysing cognitive skills and learning outcomes.

Table 1 Hara, Bonk, and Angeli's framework for analysing cognitive skills

\begin{tabular}{|c|c|c|}
\hline Reasoning Skills & Definitions & Indicators \\
\hline Elementary clarification & $\begin{array}{l}\text { Observing or studying a problem } \\
\text { identifying its elements, and } \\
\text { observing their linkages in order } \\
\text { to come to a basic understanding }\end{array}$ & $\begin{array}{l}\text { Identifying relevant elements } \\
\text { Reformulating the problem } \\
\text { Asking a relevant question } \\
\text { Identifying previously stated } \\
\text { hypotheses } \\
\text { Simply describing the subject } \\
\text { matter }\end{array}$ \\
\hline In-depth clarification & $\begin{array}{l}\text { Analyzing and understanding a } \\
\text { problem to come to an } \\
\text { understanding which sheds light } \\
\text { on the values, beliefs, and } \\
\text { assumptions which underlie the } \\
\text { statement of the problem }\end{array}$ & $\begin{array}{l}\text { Defining the terms } \\
\text { Identifying assumptions } \\
\text { Establishing referential criteria } \\
\text { Seeking out specialized } \\
\text { information } \\
\text { Summarizing }\end{array}$ \\
\hline Inferencing & $\begin{array}{l}\text { Induction and deduction, } \\
\text { admitting or proposing an idea on } \\
\text { the basis of its link with } \\
\text { propositions already admitted as } \\
\text { true }\end{array}$ & $\begin{array}{l}\text { Drawing conclusions } \\
\text { Making generalizations } \\
\text { Formulating a proposition which } \\
\text { proceeds from previous } \\
\text { statements }\end{array}$ \\
\hline Judgment & $\begin{array}{l}\text { Making decisions, statements, } \\
\text { appreciations, evaluations and } \\
\text { criticisms } \\
\text { Sizing up }\end{array}$ & $\begin{array}{l}\text { Judging the relevance of } \\
\text { solutions } \\
\text { Making value judgments } \\
\text { Judging inferences } \\
\text { "I agree, disagree,,.," }\end{array}$ \\
\hline Application of strategies & $\begin{array}{l}\text { Proposing co-ordinated actions } \\
\text { for the application of a solution, } \\
\text { or following through on a choice } \\
\text { or a decision }\end{array}$ & $\begin{array}{l}\text { Making decisions, statements, } \\
\text { appreciations, evaluations and } \\
\text { criticisms } \\
\text { Sizing up }\end{array}$ \\
\hline
\end{tabular}

Adopted and modified from Henri, 1992 
The advantage of the table is that it identifies what to be looked for in the text and the indicators for such categories. In doing a discourse analysis of the data, the research adopted the qualitative content analysis method for categorizing and delineating the data for analysis (Gunawardena \& Zittle 1996 \& Jeong, 2003). This methodology focuses on the quality of the content as a basis for analysis and is more meaningful than alternative methods such as the quantitative content analysis and the frequency count (Naranjo et al., 2011). Because this is an interpretive study, ODF posts will be retrieved and subjected to critical content analysis. The texts will be examined to uncover evidence of students' cognitive skills (Hara, Bonk, \& Angeli, 1998).

Following the receipt of electronic lecture materials via www.easyclass.com and a f $2 \mathrm{f}$ class discussion with students in the course Survey of Applied Linguistics, the students were asked to respond to the questions posted on the discussion forum. The prompts were designed to elicit students' responses which would provide evidence of students' learning, such as application of theory to practice, the abstraction of significant ideas from the text, appropriate inferences and synthesis of ideas, as well as evaluative and analytical ability. The exercise was $100 \%$ asynchronous in the sense that the students were not required to submit their posting at the same time; this was to allow them to engage in a deep reflection on the issue under focus. However, they had a timeline to submit their posting.

\section{DATA PRESENTATION AND ANALYSIS}

Only the portions of the whole texts used for analysis are presented. The full names of respondents are not used, instead, their initials (in terms of name and sex) are used. Hara, Bonk, \& Angeli's (1998) reasoning skills and their indicators are used for data analysis. The excerpts of the online discussion forum narratives are shown below. And due to space limitations, only portions of texts used for analysis are presented.

Elementary clarification and in-depth clarification strategy: This strategy is designed to help the students reflect in their online discussion forum submissions the skills to describe, to recall facts, to contrast and differentiate, to identify, to explain, and to argue.

\section{Prompt 1 - Differentiate between Applied Linguistics and Linguistics Applied}

Text 1: I will attempt to identify the difference between Linguistics Applied and Applied Linguistics by drawing reference from Brumfit (1977) and Grabe (2000). Brumfit argues that Applied Linguistics is the theoretical and empirical investigation of real world problems in which language is a central issue. Grabe (2000) opines that the focus of AL is on trying to resolve language-based problems that people encounter in the real world, whether they be learners, teachers, supervisors, academics, lawyers, service providers, those who need social services, test makers, policy developers, dictionary makers, translators, or a whole range of clients. Therefore, it can be concluded from the above postulations that AL is the use of language to solve society problems that are language-related. In contrast, linguistics applied focuses on the theoretical aspect of linguistics... O.E. (Male)

Text 2: The distinction between AL and LA can be seen in terms of their scope and general aims. While the goal of a linguist is to observe, analyse, describe and build up linguistic theories, an applied linguist goes beyond mere description of language data. An applied linguist provides a solution to problems. That is to say that an applied linguist proffers judgment (solution) on some language-related problems in the society in terms of providing 
language curriculum, language test and language policy/plan. The domain of linguistics applied is nothing but language; however, applied linguistics can look at language in various contexts of human life. For example, in the context of education/language teaching, law/crime investigations, politics, ICT, medicine translation, etc. O. L. (Female).

\subsection{Development of metacognitive awareness}

Using Hara, Bonk, \& Angeli's (1998) framework for analysing cognitive skills and learning outcomes, it can be noted from the comments that the students in texts 1 and 2 exhibited reasoning skills of elementary and in-depth clarification, as they demonstrated an understanding of the course material. The student in text 1 showed the difference between linguistics and applied linguistics by referring to Brumfit (1977) and Grabe's (2000) definition of applied linguistics. He then drew a conclusion on the difference between linguistics and applied linguistics based on the previous reference. Text 2 showed the difference between linguistics and applied linguistics by describing the scope and objectives of the two disciplines and then connected these two facts to illustrate the difference between linguistics and applied linguistics. The above submissions are a reflection of Anderson, Rourke, Garrison, and Archer's (2000) teaching presence component of CoI. For example, prior to the forum discussion, the students had received course materials in electronic format via the easyclass platform that tended to guide and support them during the course delivery. Besides, during the online discussion forum on the easyclass platform, the course instructor communicated to the students and ensured that they were aware of their responsibilities. During the online forum discussion, he answered questions from students regarding some tasks and activities they did not understand. He also communicated to the students individually when necessary, via private chat to provide needed guidance. Vygotsky describes the above comments from the students as evidence of metacognitive awareness, as the prompt and the asynchronous nature of the discussion forum gave the learners opportunity and time for deep reflection on the course work and thorough research before posting their submission.

Inference and judgment strategy: the strategy expects students to reflect the skills to assess, to evaluate, to appraise, and to summarise course contents and to deduce something from an implicitly stated evidence.

Prompt 2 - Do you support the proposition that language is acquired by imitation and that the environment contributes more to language acquisition/learning?

Text 3: Well, I believe the two theories go a long way in improving the competence of speakers of any language, either the native speaker or a second language acquirer. However, teachers of languages either first or second language who want their learners to achieve full competence would intelligently apply both theories. This comes more alive when a teacher is teaching children between infant age, he or she would get to find out that the children tend to flow in understanding very well if the use of the behaviourist theory is applied, meanwhile the mentalist theory goes very well with a more matured mind like that of the adult, nevertheless, when the two theories are applied, full competence will be achieved. A journal by Omego Christie $U$. on second language acquisition argues that it is evident that humans are affected by heredity in the same way they are affected by the environment. Many psychologists are unanimous in their view that the environment in which one finds himself contributes to one's acquisition of language. A child's natural endowment is not enough to help in second language acquisition. Therefore, for full competence of a second language to be achieved, the 
child, as Agbedo (2003.p. 74) notes, requires sustained interaction with other language users in order to bring latent language faculty into operation within a given Language. This environment can be parents, the school teacher, or peer groups.... C. G. (Female).

Text 4: Am not totally in support of the behaviorist theory. Though, language can be acquired through imitation and that the environment sometimes tends to influence how we speak and interact with people. For instance, if you are a native speaker of Igbo and you were born and brought up in Yoruba land, there is every possibility that you can speak and behave like Yoruba people. However, human beings have the innate or inborn capacity to learn a language that reflects Noam Chomsky's innateness hypothesis. I firmly believe this mentalist theory because it is the innate competence of a native speaker that will help him or her learn. Without the innate knowledge it will be difficult to learn a language one is exposed to and to adapt to a new environment one is exposed to. K. I. (Female).

\subsection{Development of higher-order and critical thinking skills}

In contrast with rote learning, the students in texts 3 and 4 demonstrated Higher-Order Thinking Skills (HOTS) by i) acknowledging the relative importance of both theories, ii) making inferences and drawing conclusions from cited sources, and iii) fusing the two seemingly opposing theories by highlighting the various contexts where the two theories can be used. The process that leads to learning must be systemic, planned and deliberate, as it involves critical, logical, reflective, metacognitive and creative thinking (King, Goodson, \& Rohani, 2011; Krathwohl, 2002). HOT requires students to manipulate and combine information and ideas to synthesize, generalize, explain, hypnotize, and arrive at some conclusion or interpretation (Ahmad et al., 2017).

Application strategy: this strategy is used to train students to apply theory to practice.

Prompt 3 - In what ways can the principle that underlies the mentalist and the input hypotheses be applied in a second/foreign language class?

Text 5: The major tenet of the mentalist theory is that everybody learns a language, not because they are subject to a similar conditioning process, but because they possess an inborn capacity that permits them to acquire a language. Therefore, teachers should not see learners as passive receivers of the teachings from them. Learners are thinking beings, active processors of information, not tabular razors. Therefore, imitation and repetition drills would not always be the best methods of language teaching especially for advanced learners. When learners come to class, they come not as clean slates that needed to be provided with information.... E. C. (Male).

Text 6: I totally agree with $E$. C. that imitation and repetition drills cannot guarantee second language acquisition. From my personal experience, I can say that my English language proficiency has improved since I gained admission. I did not improve my proficiency by mere imitation and repetition drills. I studied hard to improve my English proficiency. I make sure I attend all my classes, read all my assigned materials, do all my assignments and classwork, etc. Language teachers are expected to assess the knowledge that language learners bring to the classroom and devise activities that would help them improve their language potentials. Activities like discovery learning, project based learning, problem solving learning and task based learning.... O. K. (Male).

Text 7: According to the input hypothesis, second language learners require comprehensible input, represented by $i+1$, to move from the current level of acquisition, represented by $i$, to 
the next level of acquisition, represented by $i+1$. According to input hypothesis, a necessary condition to move from stage $i$ to stage $i+1$ is that the acquirer understands input that contains $i+1$, where 'understand' means that the acquirer focuses on meaning as opposed to form through which the message is passed. According to Krashen (1985), teachers can teach unfamiliar terms or concepts by using familiar context and things that are within the immediate environment of learners, use of illustrations and examples. For example, teaching the unfamiliar word 'Hero' by using Nelson Mandela, etc..... O. J. (Male).

Text 8: www.oxfordreference.com identifies caretaker speech as one of the pedagogical implications of the input hypothesis. It is a speech style often used by adults and older children when talking to infants or young children, characterized by shortened sentences, simplified grammar, restricted vocabulary, slow speech with many repetitions and reduplicative words. Language teachers can adopt this strategy to modify their language in order to improve communication with their learners. Language teachers are not expected to use high sounding grammar all the time with their learners. They need to use simplified words that will be easier for the learners to comprehend. Gradually they can adjust their speech to a level that is slightly above those of their learners. V. C. (Female).

\subsection{Development of collaborative learning and peer-to-peer knowledge sharing}

Text 6 in addition to demonstrating the skill of application shows an awareness of what others have posted. This is demonstrated by the expression - 'I totally agree with E. C. that imitation and repetition drills cannot guarantee second language acquisition'. This shows that the submission in text 6 is influenced by prior texts submitted by others. Seedhouse (2004) argues that an expression made by a learner in a discourse is a reflection of the learner's examination of the prior utterances of other discussants. This is a classic example of peer-to-peer knowledge sharing and interaction that takes place in an online discussion forum. Peer-to-peer interaction helps to achieve quality learning through various activities done by the learners, such as challenging and confirming each other's knowledge in open and comfortable peer interaction (Siddiqui, Miah \& Ahmad, 2019). This is perhaps challenging to achieve in a traditional classroom setting. This is also known as scaffolding, which can be achieved by peer-to-peer or teacher-to-peer interaction and knowledge sharing (Littlewood, 2006).

Students in texts 5-8 demonstrated a deep reflection of the course material by conducting in-depth research on the mentalist theory and input hypothesis, reflected on their submission before posting them on the online forum. This resonates with Anderson's et al. (2000) cognitive presence constituent of CoI model which focuses on developing critical thinking through a deep reflection and discussion of course content.

\section{DISCUSSION}

The study is set up to examine the value of the online discussion forum as a learning tool, using Anderson's et al., (2000) CoI model, and to underpin the online discussion forum as a tool for scaffolding and peer-to-peer interaction, which enhances the learning experience. To achieve the study objective of this research, the study looks at: 1) specific ways ODFs mediates the acquisition of higher cognitive functions, 2) how collaboration and peer-to-peer interaction are achieved in ODFs, and 3) how students' contributions to the ODF demonstrate a deep reflection of course materials. Reference to the data analysis is imperative to answer the above research questions and to set clear the objective of the research. 
The results from the data analysis section reveal that ODF mediated learners' acquisition of higher cognitive functions by providing the students the opportunity to reflect on the course materials, to engage in some research activities as demonstrated by the cited sources they included in their submissions, and to deeply reflect on their submissions before posting them on the discussion forum. While the student in text 1 made reference to Brumfit (1977) and Grabe (2000), students in texts 3 and 7 made references to Agbedo (2003) and Krashen (1985), respectively, to underpin their arguments. Although reference to Krashen (1985) was made in the lecture hand-out sent to the students via the easyclass platform, references from other sources were sourced and cited by the students in their submissions. ODF discourages rote learning by pushing learners to think beyond the immediate course materials that were given to them during the f2f class discussion. Learners were able to construct meaningful submissions through sustained reflection and peer-to-peer discourse. Learners' submissions in the ODF indicate that using ODFs alongside f2f classes may lead to meta-cognitive awareness, facilitated by the asynchronous nature of the discussion forum. That is consistent with previous studies (Gunawardena and Zittle 1996; Richards (2009) that have shown pedagogical value of using online discussion forums using critical components like social presence, interaction, cognitive strategies and collaborative learning.

Reference to text 6 underscores the role of ODF in mediating collaboration and peer-topeer interaction among learners. The expression "I totally agree with E. C. that imitation and repetition drills cannot guarantee second language acquisition..." shows that learners' submissions in the ODF are influenced by prior texts submitted by others. Quite a few other submissions in the ODF also show awareness of what others have posted. Texts 7 and 8 demonstrate that ODF also facilitates a constructive contribution through peer-to-peer interaction. Note that the students in texts 5, 7 and 8, showed their engagement with the course materials by applying the mentalist theory and the input hypothesis to pedagogical contexts. This finding resonates with Siddiqui, Miah and Ahmad's (2019) study, where peer-to-peer interaction helped master's level management students to engage with learning materials and practice workplace relevant skills. Peer-to-peer interaction encourages advanced and extensive reading as well as problem-solving skills among learners. Significantly, the finding of the study resonates with previous studies in which research findings indicate that peer-to-peer interaction provides workplace and transferable skills such as teamwork (Harris \& Sandor, 2007; Siddiqui, Miah \& Ahmad, 2019).

The findings of the study also demonstrate evidence of deep reflection of course contents. For example, the student in text 2 showed the difference between linguistics and applied linguistics by: i) researching the two fields of endeavor in terms of their scope, and ii) describing the functions of an applied linguist and a linguist. Students in texts 4 and 6 demonstrated their understanding of the course materials by drawing a reference from practical and personal experiences. Students in texts 1, 3 and 8, consulted sources not cited in the lecture materials sent via the easyclass platform. The social presence (i.e. the creation of the online discussion forum) and the teaching presence (i.e. access to course materials in electronic format prior to class discussion, $\mathrm{f} 2 \mathrm{f}$ class discussion and instructor guidance on the ODF) provided the springboard for the cognitive presence (i.e. metacognitive awareness, higher-order and critical thinking skills, collaborative learning and peer-to-peer knowledge sharing). The result of the study resonates with those of Baron and Maier (2004). They argue that the asynchronous nature of the discussion board (a variant of ODF) and email provided the students opportunity to engage in the discussion in a more reflective manner, as they have access to unlimited data sources. 


\section{CONCLUSION}

The findings of the study have demonstrated evidence of metacognitive skills and critical thinking skills, which are facilitated by the asynchronous nature of the discussion forum, as it gives learners sufficient time to engage in thorough research and careful thought before posting their submission. The findings also demonstrated that teacher-topeer and peer-to-peer knowledge dissemination is best stimulated using the ODF, as it gives learners opportunities to participate actively and to collaborate with their peers in the learning process. ODF provides learners, especially the shy ones, the chance to participate in the learning process fully. It also brings out the best in learners as they have the opportunity to respond to questions and discussions more reflectively as opposed to the random and unsystematic approach that characterises the traditional f2f discussion.

Major contribution that the present study has made to the existing literature is its demonstration of the effect of ODF on learners' metacognitive awareness, higher-order thinking skills and collaborative learning. The study also reveals that ODF discourages rote learning and memorization-based learning and assessment, as questions and discussions are designed to draw learners out of their comfort zones. ODF is a tool for scaffolding and peer-to-peer interaction, which enhances the learning experience. It is undoubtedly a technological tool to impact text creation, critical thinking, and other cognitive skills. While it can be argued from the present study that ODF discourages rote or memorization-based learning, there is a need for more carefully designed studies to further investigate the effects of ODF on learners' cognitive skills and second or foreign language acquisition of use tense and article via online feedback.

\section{REFERENCES}

Ahmad, S., Prahmana, R. C. I., Kenedi, A.K., Helsa, Y., and Zainil, M. (2017). The instruments of higher order thinking skills. Journal of Physics: Conf. Series 943 (2017)

Allan, M. (2004) "A peek into the life of online learning discussion forums: Implications for web-based distance learning. International Review of Research in Open and Distance Learning, Volume 5, Number 2.

Baron, J., \& Maier. H. R. (2004). A community of inquiry evaluation of Mekong e-Sim: An online collaborative simulation. Paper presented at the ICET2004 conference, September 9.11, Singapore.

Baron, J., \& Maier. H. R. (2005). Developing online roleplay simulations for preparing engineering students for multidisciplinary and international practice. https://www.researchgate.net/publication/228628954_Developing_Online_Roleplay_ Simulations_for_Preparing_Engineering_Students_for_Multidisciplinary_and_Interna tional_Practice (Retrieved November 18, 2019).

Cheng, C. K., Pare, D. E., Collimore, L. M., \& Joordens, S. (2010). Assessing the effectiveness of a voluntary online discussion forum on improving students' course performance. Computers and Education, 56 (1), 253-261.

Dooga, J.T. (2010) "A discourse analysis of a forum discussion in moodle" in Adagunodo E.R., Adeyanju J.O., Akinmade C.T. Aderoumu G.A., and Oluwatope A.O. (eds.) AICCTRA 2010 Proceedings, Pp. 43-54. 
Frazer, C., Sullivan, D. H., Weatherspoon, D., \& Hussey, L. (2017). Faculty perceptions of online teaching effectiveness and indicators of quality. Nursing Research and Practice, 2017, 1-6.

Garrison, D. R., Anderson, T., and Archer, W. (2000). Critical inquiry in a text-based environment: computer conferencing in higher education. The Internet and Higher Education 2(2-3): 87-105.

Garrison, D., \& Anderson, T. (2003). E-learning in the 21st century: A framework for research and practice. London: RoutledgeFalmer and Taylor \& Francis Group.

Green, R. A., Farchione, D., Hughes, D. L., \& Chan, S. (2014). Participation in asynchronous online discussion forums does improve student learning of grossanatomy. Anatomical Sciences Education, 7, 71-76.

Gunawardena, C. N., \& Zittle, F. J. (1997). Social presence as a predictor of satisfaction within a computer-mediated conferencing environment. The American Journal of Distance Education 11(3):8-26.

Hardman, J. (2010) "The developmental impact of communicative interaction" in Hook, D., Franks, B., and Bauer, M. (eds) Communication, Culture and Social Change: The Social Psychological Perspective. Palgrave.

Harris, N. \& Sandor, M. (2007). Developing online discussion forums as student centred peer e-learning environments. https://www.researchgate.net/publication/29466076_Developing _online_discussion_forums_as_student_centred_peer_e-learning_environments (Retrieved December 18, 2019).

Hawkins, B. L., \& Rudy, J. A. (2008). EDUCAUSE core data service: Fiscal year 2007 summary report. https://www.researchgate.net/publication/234634202_EDUCAUSE_ Core_Data_Service_Fiscal_Year_2007_Summary_Report (Retrieved December 18, 2019).

Hu, Q, Huang, Y. \& Deng, L. (2018). A Method for analysis of online discussion forum in moodLe. A paper presentation at the 13th International Conference on Computer Science \& Education (ICCSE).

Jeong, A. C. (2003). "The sequential analysis of group interaction and critical thinking in online threaded discussions." The American Journal of Distance Education, 17(1), 25-43.

Kanuka, H. \& Anderson, T. (1998). Online social interchange, discord, and knowledge construction. Journal of Distance Education. 13 (1) pp. 57-74.

King, F., Goodson, L., \& Rohani, F. (2011). Higher order thinking skills: Definitions, strategies, assessment. Center for Advancement of Learning and Assessment. Tallahassee, FL: Florida State University.

Kozulin, A. (2003). "Psychological tools and mediated learning" in Kozulin, A., Gindis, B., Ageyev, V.V., Miller, S.M., Vygotsky's educational theory in cultural context. Cambridge: Cambridge University Press.

Krathwohl, D. R. (2002). A revision of Bloom's taxonomy: An overview. Theory into practice, 41(4), 212-218.

Littlewood, W. (2006) "Second language learning" in Alan Davies and Catherine Elder (eds.) The Handbook of Applied Linguistics (pp. 501-524).

Lucy , J. and Wertsch, J. (1987) "Vygotsky and Whorf: A comparative analysis" in M. Hickmann (ed.), Social and functional approaches to language and thought (pp. 6786): New York: Academic Press.

Marra, R. M., Moore, J.L. and Klimczak, A.K. (2004). "Content analysis of online discussion forums: A comparative analysis of protocols" ETR\&D, Vol. 52, No. 2 Pp. 23-40. 
Nandi, D., Chang, S., \& Balbo, S. (2009). A conceptual framework for assessing interaction quality in online discussion forums, In Same places, different spaces. Proceedings Ascilite Auckland 2009.

Nandi, D., Hamilton, M., Harland, J., Warburton, G. (2011). How active are students in online discussion forums. https://www.researchgate.net/publication/284312554_How_active_are_ students_in_online_discussion_forums [Retrieved February 25, 2020]

Naranjo, M., Javier, O. \& Segués, T. (2011). Participation and cognitive quality profiles in an online discussion forum. British Journal of Educational Technology 43(2):282-294

Richards, I.G. (2009). Effective use of online discussion forums: The importance of assessment. https://www.researchgate.net/publication/242548101_Effective_Use_of_ Online_Discussion_Forums_The_Importance_of_Assessment [Retrieved February 25, 2020]

Romero, C., López, M., Luna, J., \& Ventura, S. (2013). Predicting students' final performance from participation in online discussion forums. Computers \& Education, 68,458-472.

Seedhouse, P. (2004). The interactional architecture of the language classroom: A conversation analysis perspective. Main Street, MA, USA: Blackwell Publishing: Blackwell.

Siddiqui, N., Miah, K., Ahmad, A. (2019). Peer to peer synchronous interaction and student engagement: A perspective of postgraduate management students in a developing country. https://www.researchgate.net/publication/334426064_Peer_to_Peer_Synchronous_Interac tion_and_Student_Engagement_A_Perspective_of_Postgraduate_Management_Students_ in_a_Developing_Country [Retrieved May 17, 2020]

Tan, K. E. (2016). Using online discussion forums to support learning of paraphrasing: Online discussion forums for learning paraphrasing. British Journal of Educational Technology 48(6).

Vygotsky, L. S. (1978). Mind in society: The development of higher psychological processes (edited by M. Cole, V. John-Steiner, S. Scribner, \& E. Souberman). Cambridge, MA: Harvard University Press. 